\title{
Effects of Low-Temperature Sintering on Varistor Properties and Stability of VMCDNB-Doped Zinc Oxide Ceramics
}

\author{
Choon-W. Nahm ${ }^{\dagger}$ \\ Semiconductor Ceramics Laboratory, Department of Electrical Engineering, Dongeui University, Busan 47340, Korea \\ (Received November 8, 2018; Revised January 10, 2019; Accepted January 12, 2019)
}

\begin{abstract}
The varistor properties and stability against dc-accelerated stress of $\mathrm{V}_{2} \mathrm{O}_{5}-\mathrm{Mn}_{3} \mathrm{O}_{4}-\mathrm{Co}_{3} \mathrm{O}_{4}-\mathrm{Dy}_{2} \mathrm{O}_{3}-\mathrm{Nb}_{2} \mathrm{O}_{5}-\mathrm{Bi}_{2} \mathrm{O}_{3}$ (VMCDNB)-doped zinc oxide ceramics sintered at $850-925^{\circ} \mathrm{C}$ were investigated. Increasing the sintering temperature increased the average grain size from 4.6 to $8.7 \mathrm{~mm}$ and decreased the density of the sintered pellet density from 5.54 to $5.42 \mathrm{~g} / \mathrm{cm}^{3}$. The breakdown field decreased from 5919 to $1465 \mathrm{~V} / \mathrm{cm}$ because of the increase in the average grain size. Zinc oxide ceramics sintered at $875^{\circ} \mathrm{C}$ showed the highest nonlinear coefficient (43.6) and the highest potential barrier height $(0.96 \mathrm{eV})$. Zinc oxide ceramics sintered at $850^{\circ} \mathrm{C}$ showed the highest stability: the variation rate of the breakdown field was $-2.0 \%$ and the variation rate of the nonlinear coefficient was $-23.3 \%$, after application of the specified stress (applied voltage/temperature/time).
\end{abstract}

Key words : Sintering temperature, Electrical properties, Stress, Varistors

\section{Introduction}

$\mathbf{I}_{\mathrm{t} t}^{\mathrm{n}}$ today's complex information society, the importance of the reliability of electronic components and electrical and electronic equipment must be emphasized more than ever. A reliable system maintains stability under complex circumstances; the system should be not disturbed from external circumstances, in particular, transient and overvoltage. However, a semiconductor circuit system is very sensitive to overvoltage. As a result, devices or systems can malfunction or be destroyed by overvoltage. Therefore, surge protection devices (SPDs) must be embedded into systems. The core element of an SPD is a varistor.

A varistor is a semiconductor device, in which the current nonlinearly varies with voltage. ${ }^{1)}$ If the nonlinear coefficient, which shows the degree of nonlinearity, is high, it can define the varistor as follows. The varistor will play a role as an insulator at a lower voltage than the breakdown voltage, and a conductor at a higher voltage than the breakdown voltage.

Most reported varistor materials have been Bi-doped zinc oxide $^{1-7)}$ and Pr-doped zinc oxide. ${ }^{8-10)}$ These materials need high sintering temperatures of more than $1000^{\circ} \mathrm{C}$. An internal electrode to fabricate a multilayered varistor is necessarily needed. Thus, in general, the internal electrode is formed using expensive $\mathrm{Pt}$ or $\mathrm{Pd}$. Alternative varistor materials are vanadium-added zinc oxide varistor ceramics. ${ }^{11,12)}$ These have a lower sintering temperature using the low melting point $\left(690^{\circ} \mathrm{C}\right)$ of vanadium oxide $\left(\mathrm{V}_{2} \mathrm{O}_{5}\right)$. The history

\footnotetext{
${ }^{\dagger}$ Corresponding author: Choon-W. Nahm

E-mail : cwnahm@deu.ac.kr

Tel : +82--51-890-1669 Fax : +82-505-182-6900
}

of so-called $\mathrm{ZnO}-\mathrm{V}_{2} \mathrm{O}_{5}$-based varistor ceramics is much shorter than that of zinc-bismuth-based and zinc-praseodymium-based ceramics. Nevertheless, the technology is advanced using existing varistor technology.

Until now, nonlinearity has been considerably improved whereas stability has not. ${ }^{13-15)}$ A complex process using diverse additives and sintering processes should be continuously conducted to enhance varistor characteristics. The ceramic composition used in this study was selected on the basis of its nonlinear properties, microstructure, stability, etc. ${ }^{13-19)} \mathrm{We}$ introduce a $\mathrm{V}_{2} \mathrm{O}_{5}-\mathrm{Mn}_{3} \mathrm{O}_{4}-\mathrm{Co}_{3} \mathrm{O}_{4}-\mathrm{Dy}_{2} \mathrm{O}_{3}-\mathrm{Nb}_{2} \mathrm{O}_{5^{-}}$ $\mathrm{Bi}_{2} \mathrm{O}_{3}$ (VMCDNB)-doped zinc oxide varistor ceramic exhibiting a relatively high stability.

\section{Experimental Procedure}

\subsection{Sample preparation process}

Analytic grade powder materials for the varistor, i.e. 98.25 $\mathrm{mol} \% \mathrm{ZnO}+0.5 \mathrm{~mol} \% \mathrm{~V}_{2} \mathrm{O}_{5}+0.5 \mathrm{~mol} \% \mathrm{Mn}_{3} \mathrm{O}_{4}+0.5 \mathrm{~mol} \%$ $\mathrm{Co}_{3} \mathrm{O}_{4}+0.1 \mathrm{~mol} \% \mathrm{Dy}_{2} \mathrm{O}_{3}+0.1 \mathrm{~mol} \% \mathrm{Nb}_{2} \mathrm{O}_{5}+0.05 \mathrm{~mol} \%$ $\mathrm{Bi}_{2} \mathrm{O}_{3}$, were prepared. The varistor devices were created using the traditional ceramics method. The balanced raw materials were ball milled for $24 \mathrm{~h}$ with acetone in a polypropylene bottle. The mixture was dried at $120^{\circ} \mathrm{C}$ in a dry oven. The mixture was blended with polyvinyl butyral (PVB) and granulated using a sieve shaker to obtain a starting powder. The granulated powder was pressed into pellets (approximately $10 \mathrm{~mm}$ in diameter and approximately 1.5 $\mathrm{mm}$ in thickness) by uniaxial pressing $\left(1000 \mathrm{~kg} / \mathrm{cm}^{2}\right)$. The pellets, set on a stabilized $\mathrm{MgO}$ plate after burning out the polyvinyl butyral (PVB) binder at $600^{\circ} \mathrm{C}$ for $1 \mathrm{~h}$, were sintered at various temperatures, i.e. $850,875,900$, and $925^{\circ} \mathrm{C}$, for $3 \mathrm{~h}$. The sintered pellets were lapped and polished into a 
specified dimension (approximately $8 \mathrm{~mm}$ in diameter and approximately $1.0 \mathrm{~mm}$ in thickness). The final pellets were coated with conductive $\mathrm{Ag}$ paste and then fired at $550^{\circ} \mathrm{C}$ for $10 \mathrm{~min}$.

\subsection{Microstructure examination}

The sintered pellets were lapped and polished, and then were etched using $1 \mathrm{HClO}_{4}: 1000 \mathrm{H}_{2} \mathrm{O}$ solution (v/v). A fracture microstructure image of the sintered pellets was obtained using field emission scanning electron microscopy (SEM; Quanta 200). The average grain size $(d)$ was calculated using the following expression proposed by Wurst et $a l .^{20)}$ :

$$
d=\frac{1.56 L}{M N}
$$

where $L$ is the random line length on the micrograph, $M$ is the magnification of the micrograph, and $N$ is the number of the grain boundaries intercepted by the lines.

The X-ray diffraction patterns of the sintered pellets were obtained using $\mathrm{CuK} \alpha$ radiation (X'pert-PRO MPD). The densities $(\rho)$ of the sintered pellets were obtained using a density determination kit (238490) attached to a balance (AG 245).

\subsection{J-E characteristics measurement}

The current-voltage $(I-V)$ characteristic data were automatically measured by voltage sourcing and current measuring using a source/measure unit (SMU; Keithley 237). The varistor voltage $\left(V_{1 \mathrm{~mA} / \mathrm{cm}^{2}}\right)$ was obtained at $1.0 \mathrm{~mA} / \mathrm{cm}^{2}$ in the current density. The leakage current $\left(I_{\mathrm{L}}\right)$ was obtained at 0.8 times the $V_{1 \mathrm{~mA} / \mathrm{cm}^{2}}$. The breakdown field $\left(E_{1 \mathrm{~mA} / \mathrm{cm}^{2}}\right)$, the nonlinear coefficient $(\alpha),{ }^{1)}$ and the leakage current density $\left(J_{\mathrm{L}}\right)$ were calculated using the following expressions:

$$
\begin{aligned}
& E_{1 \mathrm{~mA} / \mathrm{cm}^{2}}=\frac{V_{1 \mathrm{~mA} / \mathrm{cm}^{2}}}{t} \\
& \alpha=\frac{1}{\log \left(V_{10 \mathrm{~mA} / \mathrm{cm}^{2}} / V_{1 \mathrm{~mA} / \mathrm{cm}^{2}}\right)} \\
& J_{\mathrm{L}}=\frac{I_{\mathrm{L}}}{A}
\end{aligned}
$$

where $t$ is the thickness of the specimen $(1 \mathrm{~mm})$ and $A$ is the area of the electrode.

\section{4. $C$-V characteristics measurement}

The capacitance-voltage $(C$ - $V)$ characteristics were measured using a precision (LCR) meter (QuadTech 7600) and an electrometer (Keithley 617). The donor concentration $N_{\mathrm{d}}$ and the barrier height $\Phi_{\mathrm{b}}$ were determined using the following expression: ${ }^{21)}$

$$
\left(\frac{1}{C_{b}}-\frac{1}{2 C_{b o}}\right)^{2}=\frac{2}{q \varepsilon N_{d}}\left(\Phi_{b}+V_{g}\right)
$$

where $C_{\mathrm{b}}$ is the capacitance per unit area of a grain bound- ary, $C_{\mathrm{bo}}$ is the value of $C_{\mathrm{b}}$ when $V_{\mathrm{g}}=0, V_{\mathrm{g}}$ is the applied voltage per grain boundary, $q$ is the electronic charge, and $e$ is the permittivity of $\mathrm{ZnO}\left(\varepsilon=8.5 \varepsilon_{0}\right)$.

The density of the interface state $N_{\mathrm{t}}$ at the grain boundary was calculated using the following expression: ${ }^{21)}$

$$
N_{\mathrm{t}}=\sqrt{\frac{2 \varepsilon N_{\mathrm{d}} \Phi_{\mathrm{b}}}{q}}
$$

\subsection{Degradation characteristics measurement}

The degradation characteristics were measured under

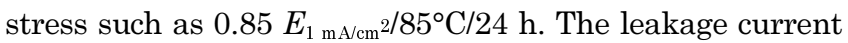
$\left(I_{\mathrm{L}}\right)$ flowing through the varistor was measured every $1 \mathrm{~min}$ during the stress by voltage sourcing and current measuring using an SMU (Keithley 237). The degradation rate coefficient $\left(K_{\mathrm{T}}\right)$ was calculated using the following expression: $^{22)}$

$$
I_{\mathrm{L}}=I_{\mathrm{Lo}}+K_{\mathrm{T}} t^{1 / 2}
$$

where $I_{\mathrm{Lo}}$ is $I_{\mathrm{L}}$ at $t=0$.

\section{Results and Discussion}

Figure 1 illustrates the SEM micrographs of the specimens at various sintering temperatures. On the whole, the grain size of the sintered pellets increased with the increase in sintering temperature. The average grain size $(d)$ of the specimens significantly increased from 4.6 to $8.7 \mathrm{~mm}$, despite the various sintering temperatures of the narrow gap. However, the density $(\rho)$ of the sintered pellets decreased from 5.53 to $5.40 \mathrm{~g} / \mathrm{cm}^{3}$ (theoretical density $=5.78 \mathrm{~g} / \mathrm{cm}^{3}$ in zinc oxide) with the increase in sintering temperature. It is presumed that the reduction in the density of the sintered pellets can be ascribed to the result of the volatility of $\mathrm{ZnV}_{2} \mathrm{O}_{4}$ (see Fig. 2 in advance). The detailed average grain size and density of the sintered pellets at various sintering temperatures are presented in Table 1.

Figure 2 illustrates the X-ray diffraction patterns of the specimens at various sintering temperatures. Minor phases such as the zinc vanadate oxides $\left(\mathrm{Zn}_{3}\left(\mathrm{VO}_{4}\right)_{2}, \mathrm{ZnV}_{2} \mathrm{O}_{4}\right)$, vanadium oxide $\left(\mathrm{VO}_{2}\right)$, and dysprosium vanadate $\left(\mathrm{DyVO}_{4}\right)$ were generated. The peak of $\mathrm{ZnV}_{2} \mathrm{O}_{4}$ gradually diminished with the increase in sintering temperature. $\mathrm{ZnV}_{2} \mathrm{O}_{4}$ most likely volatilizes with of the increase in sintering temperature, despite the various sintering temperatures of the narrow gap. Therefore, $\mathrm{ZnV}_{2} \mathrm{O}_{4}$ can affect the sintered density, electrical properties, and stability. In contrast, $\mathrm{DyVO}_{4}$ seems to be considerably stable by indicating the same peak with the increase in sintering temperature.

Figure 3 illustrates the electric field-current density $(E-J)$ characteristics of the specimens at various sintering temperatures. The non-ohmicity results from the varistor affect in $E$ - $J$ characteristics. That is, the $E$ - $J$ characteristics are nonlinear in the first and third quadrants. Specifically, the current is nearly zero before reaching a breakdown, and it is almost infinite after reaching a breakdown. The breakdown 

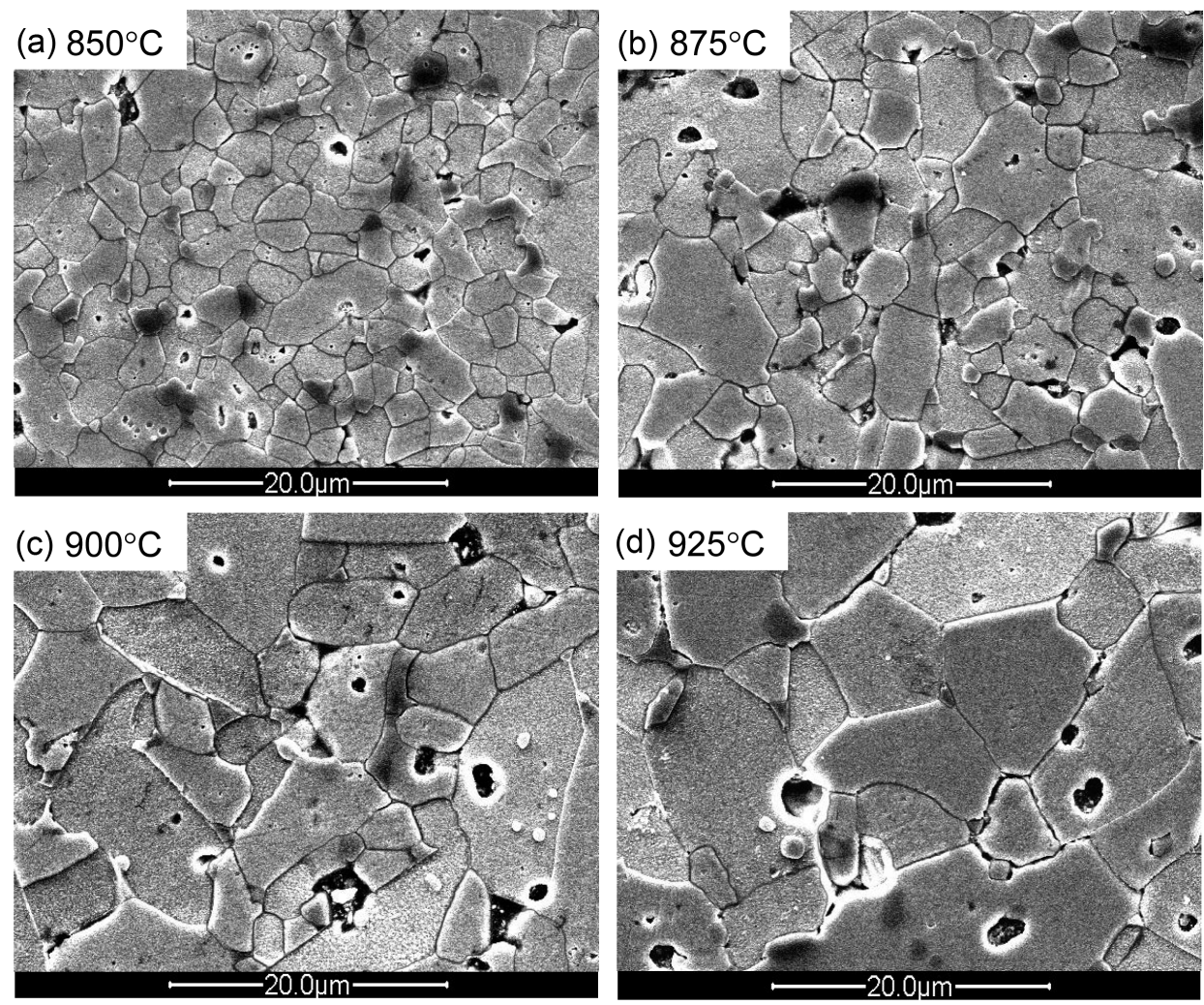

Fig. 1. SEM micrographs of VMCDNB-doped $\mathrm{ZnO}$ ceramics sintered at various temperatures: (a) $850^{\circ} \mathrm{C}$, (b) $875^{\circ} \mathrm{C},\left(\right.$ c) $900^{\circ} \mathrm{C}$, and (d) $925^{\circ} \mathrm{C}$.

Table 1. Microstructure and Electrical Parameters of VMCDNB-doped ZnO Ceramics Sintered at Different Temperatures

\begin{tabular}{cccccccccc}
\hline $\begin{array}{c}\text { Sintering } \\
\text { temp. }\left({ }^{\circ} \mathrm{C}\right)\end{array}$ & $\begin{array}{c}d \\
(\mu \mathrm{m})\end{array}$ & $\begin{array}{c}\rho \\
\left(\mathrm{g} / \mathrm{cm}^{3}\right)\end{array}$ & $\begin{array}{c}E_{1 \mathrm{~mA} / \mathrm{cm}^{2}} \\
(\mathrm{~V} / \mathrm{cm})\end{array}$ & $\begin{array}{c}v_{\mathrm{gb}} \\
(\mathrm{V} . \mathrm{gb})\end{array}$ & $\alpha$ & $\begin{array}{c}J_{\mathrm{L}} \\
\left(\mu \mathrm{A} / \mathrm{cm}^{2}\right)\end{array}$ & $\begin{array}{c}N_{\mathrm{d}} \\
\left(10^{18} \mathrm{~cm}^{-3}\right)\end{array}$ & $\begin{array}{c}\Phi_{\mathrm{b}} \\
\mathrm{eV}\end{array}$ & $\begin{array}{c}N_{\mathrm{t}} \\
\left(10^{12} \mathrm{~cm}^{-2}\right)\end{array}$ \\
\hline 850 & 4.6 & 5.54 & 5919 & 2.7 & 39.1 & 35.7 & 0.77 & 0.87 & 2.51 \\
875 & 6.1 & 5.48 & 3370 & 2.0 & 43.6 & 28.2 & 0.98 & 0.96 & 2.96 \\
900 & 7.2 & 5.44 & 1871 & 1.3 & 37.2 & 63.0 & 1.45 & 0.84 & 3.38 \\
925 & 8.7 & 5.42 & 1465 & 1.3 & 33.3 & 74.1 & 1.77 & 0.80 & 3.64 \\
\hline
\end{tabular}

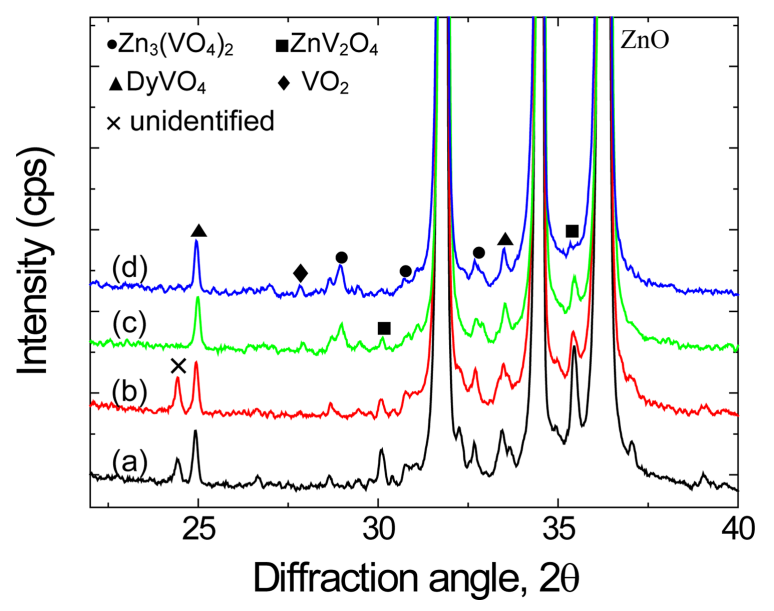

Fig. 2. XRD patterns of VMCDNB-doped $\mathrm{ZnO}$ ceramics sintered at various temperatures: (a) $850^{\circ} \mathrm{C}$, (b) $875^{\circ} \mathrm{C}$ (c) $900^{\circ} \mathrm{C}$, and (d) $925^{\circ} \mathrm{C}$. field $\left(E_{1 \mathrm{~mA} / \mathrm{cm}^{2}}\right)$ significantly decreased from 5919 to $1465 \mathrm{~V} /$ $\mathrm{cm}$ with the increase in sintering temperature. The changing tendency of $E_{1 \mathrm{~mA} / \mathrm{cm}^{2}}$ was analyzed using the following expression:

$$
E_{1 \mathrm{~mA} / \mathrm{cm}^{2}}=\frac{v_{\mathrm{gb}}}{d}
$$

where $v_{\mathrm{gb}}$ is the breakdown voltage per grain boundary and $d$ is the average grain size. $E_{1 \mathrm{~mA} / \mathrm{cm}^{2}}$ is directly determined by the $d$ and $v_{\mathrm{gb}}$ values. Among them, the average grain size absolutely affects the $E_{1 \mathrm{~mA} / \mathrm{cm}^{2}}$. Therefore, the reduction in $E_{1 \mathrm{~mA} / \mathrm{cm}^{2}}$ can be ascribed to the increase in the average grain size with the increase in sintering temperature.

The nonlinear coefficient $(\alpha)$ increased from 39.1 to 43.6 when the sintering temperature reached $875^{\circ} \mathrm{C}$. When the sintering temperature exceeded $875^{\circ} \mathrm{C}, \alpha$ showed a decreasing tendency and diminished to 33.3 at $925^{\circ} \mathrm{C}$. In the low field below the breakdown field, the current is dominated by 


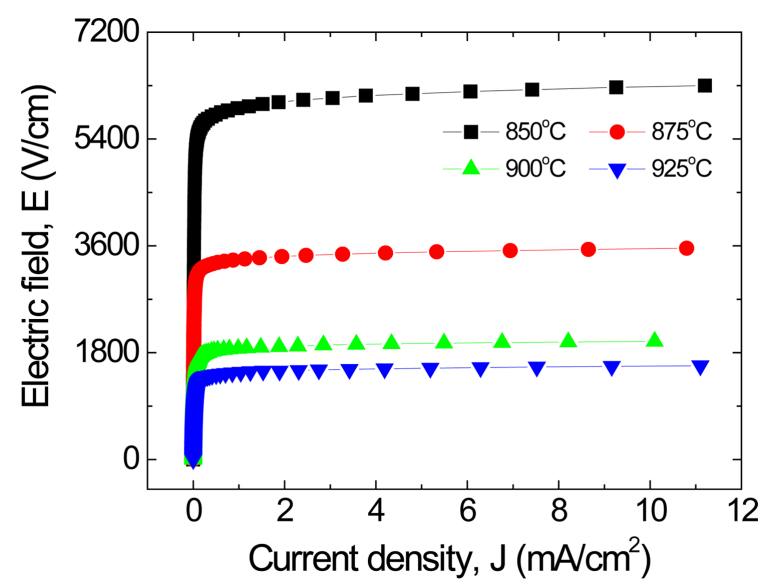

Fig. 3. $E$ - $J$ characteristics of VMCDNB-doped $\mathrm{ZnO}$ ceramics sintered at different temperatures.

a thermionic emission mechanism, in which the electron is over the potential barrier. In the high field above the breakdown field, the current is dominated by a quantum mechanical tunneling mechanism, in which the electron is through the potential barrier. $\alpha$ is determined by the ratio of the tunneling to the thermionic emission. If the tunneling mechanism is much more predominant than the thermionic emission mechanism, a high $\alpha$ is obtained. Therefore, the higher the barrier, the higher the $\alpha$. However, the leakage current density $\left(J_{\mathrm{L}}\right)$ decreased from 35.7 to $28.2 \mu \mathrm{A} / \mathrm{cm}^{2}$ when the sintering temperature reached $875^{\circ} \mathrm{C}$. When the sintering temperature exceeded $875^{\circ} \mathrm{C}, J_{\mathrm{L}}$ increased to 74.1 $\mu \mathrm{A} / \mathrm{cm}^{2}$ at $925^{\circ} \mathrm{C}$. The $J_{\mathrm{L}}$ value of the specimen sintered at $875^{\circ} \mathrm{C}$ is a low value comparable to that of $\mathrm{ZnO}-\mathrm{V}_{2} \mathrm{O}_{5}$-based varistors, which have showed the lowest value until now. ${ }^{14)}$ On the whole, the low leakage current is the important feature of this system. The detailed values of $E_{1 \mathrm{~mA} / \mathrm{cm}^{2}}, \alpha$, and $J_{\mathrm{L}}$ are presented in Table 1.

Figure 4 shows the modified $C$ - $V$ characteristics of the specimens at various sintering temperatures. Most of the applied voltage is dropped to the depletion layer width at

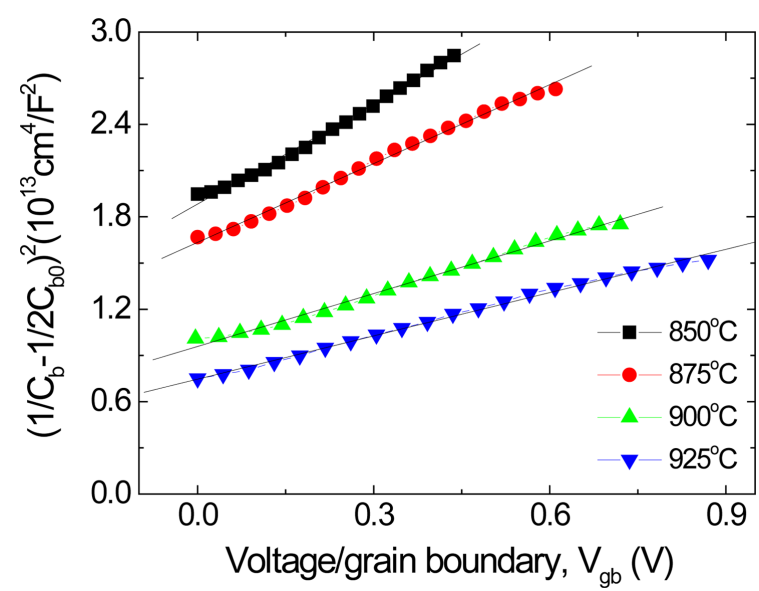

Fig. 4. $C-V$ characteristics of VMCDNB-doped $\mathrm{ZnO}$ ceramics sintered at different temperatures. the grain boundaries. The variation in the space charge within the depletion layer varies the capacitance. Therefore, the donor density $\left(N_{\mathrm{d}}\right)$, barrier height $\left(\Phi_{\mathrm{b}}\right)$, and density of the interface states $\left(N_{\mathrm{t}}\right)$ can be obtained through the variation in the capacitance. $N_{\mathrm{d}}$ is obtained from the slope of the curves. As a result, $N_{\mathrm{d}}$ showed a fluctuation between $0.77 \times 10^{17} \mathrm{~cm}^{-3}$ and $1.77 \times 10^{17} \mathrm{~cm}^{-3}$. However, on the whole, $N_{\mathrm{d}}$ seems to increase with the increase in sintering temperature. $\Phi_{\mathrm{b}}$ increased from 0.87 to $0.96 \mathrm{eV}$ when the sintering temperature reached $875^{\circ} \mathrm{C}$. When the sintering temperature exceeded $875^{\circ} \mathrm{C}, \Phi_{\mathrm{b}}$ diminished to $0.80 \mathrm{eV}$ at $925^{\circ} \mathrm{C}$. The changing tendency of $\Phi_{b}$ is equal to that of the nonlinear coefficient. Therefore, the nonlinear properties depend on the potential barrier in the $C$ - $V$ characteristics.

Figure 5 shows the trend of the leakage current $\left(I_{\mathrm{L}}\right)$ when the specimens are subjected to direct current (DC) stress

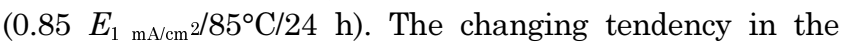
leakage current $\left(I_{\mathrm{L}}\right)$ showed a positive creep phenomenon in which the leakage current increases with increasing stress time for all specimens. The degradation was estimated by the slope $K_{\mathrm{T}}$ of the $t^{1 / 2}-I_{\mathrm{L}}$ curves. $K_{\mathrm{T}}$ increased with the increase in sintering temperature. The initial leakage current of the specimen sintered at $875^{\circ} \mathrm{C}$ was the lowest, whereas the $K_{\mathrm{T}}$ value $\left(1.38 \mu \mathrm{A} \cdot \mathrm{h}^{-1 / 2}\right)$ of the specimen sintered at $850^{\circ} \mathrm{C}$ was the lowest. In light of the $K_{\mathrm{T}}$ value, the specimen sintered at $850^{\circ} \mathrm{C}$ seems to be the most stable.

Figure 6 illustrates the changing tendency of the $E-J$ characteristic curves after stress, when compared to the initial curves of the specimens at various sintering temperatures. Comparing the initial and stressed curves, the difference, in common, is shown in the vicinity of the knee. The variation is gradually greater with the increase in sintering temperature. The changing tendency of the curves coincides with that of $K_{\mathrm{T}}$. The specimen sintered at $850^{\circ} \mathrm{C}$ has the highest stability and the specimen sintered at $925^{\circ} \mathrm{C}$ has the lowest stability.

Figure 7 shows $E_{1 \mathrm{~mA} / \mathrm{cm}^{2}}$ and $\alpha$ of the stressed specimens at various sintering temperatures. Apparently, all the speci-

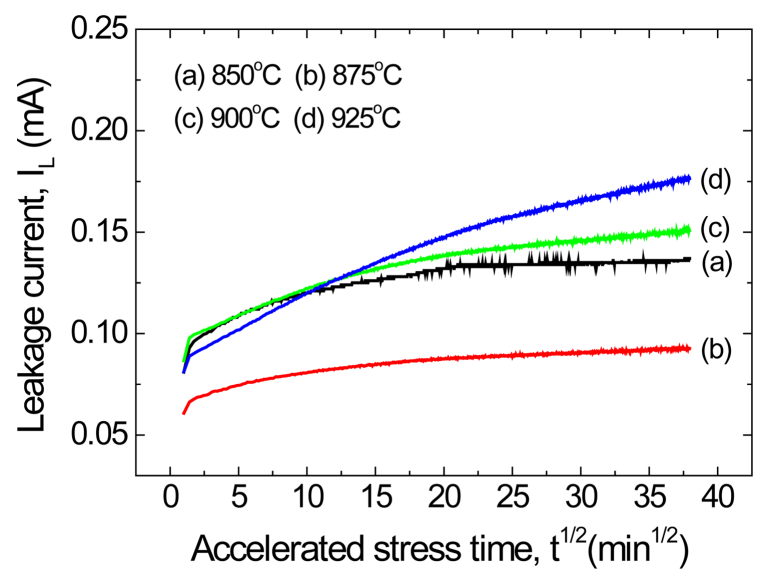

Fig. 5. Leakage current behavior during DC accelerated stress of VMCDNB-doped $\mathrm{ZnO}$ ceramics sintered at different temperatures. 

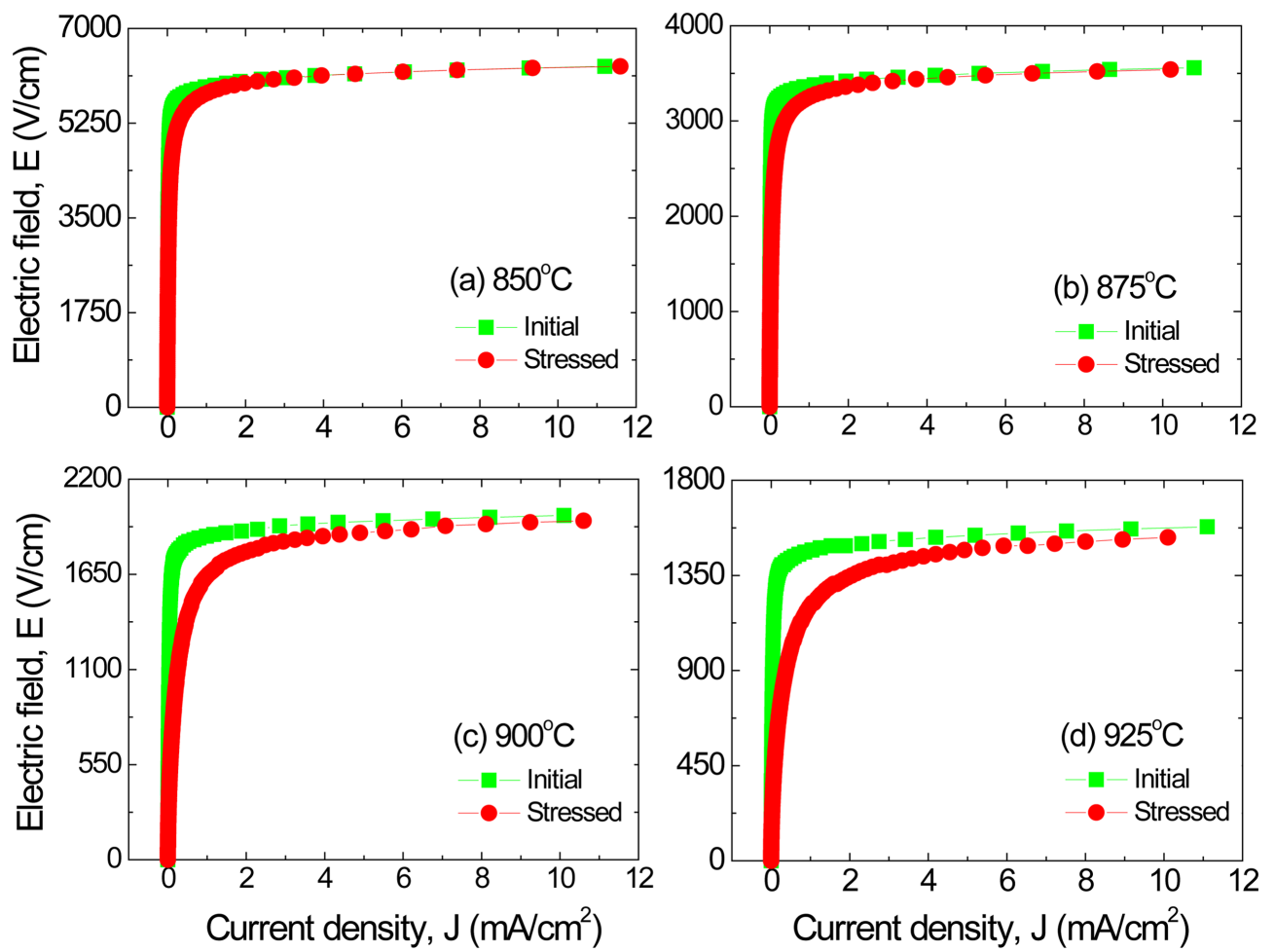

Fig. 6. $E-J$ characteristic behavior before and after DC accelerated stress of VMCDNB-doped ZnO ceramics sintered at different temperatures.
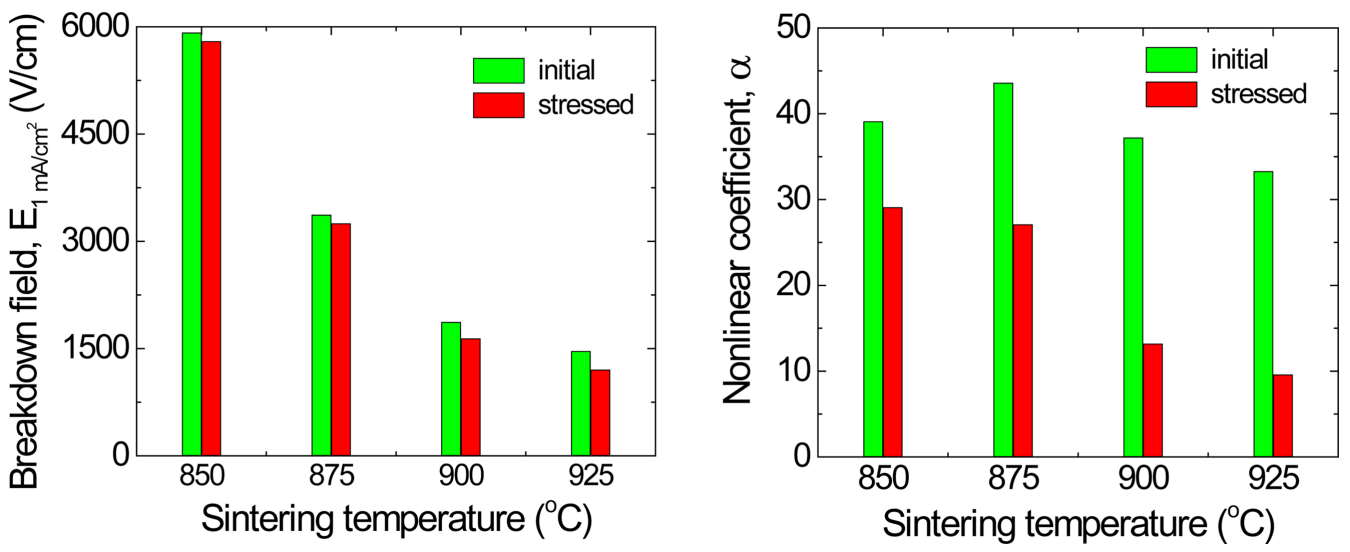

Fig. 7. Breakdown field (a) and nonlinear coefficient (b) before and after DC accelerated stress of VMCDNB-doped ZnO ceramics sintered at different temperatures.

mens showed a reduction in $E_{1 \mathrm{~mA} / \mathrm{cm}^{2}}$ after a stress. However, the amount of the reduction differed for each specimen, and gradually increased with the increase in sintering temperature. The specimen sintered at $850^{\circ} \mathrm{C}$ showed the lowest reduction rate of $E_{1 \mathrm{~mA} / \mathrm{cm}^{2}}$ with $\Delta E_{1 \mathrm{~mA} / \mathrm{cm}^{2}} / E_{1 \mathrm{~mA} / \mathrm{cm}^{2}}=-2 \%$. However, the specimens exceeding $900^{\circ} \mathrm{C}$ in sintering temperature showed a large reduction rate, reaching $\Delta E_{1 \mathrm{~mA} / \mathrm{cm}^{2} /}$ $E_{1 \mathrm{~mA} / \mathrm{cm}^{2}}>-10 \%$. Meanwhile, the variation rate of $\alpha$ also had the same changing tendency as that of $E_{1 \mathrm{~mA} / \mathrm{cm}^{2}}$ with the increase in sintering temperature. However, the reduction rate of $\alpha$ was much larger than that of $E_{1 \mathrm{~mA} / \mathrm{cm}^{2}}$. The specimen sintered at $850^{\circ} \mathrm{C}$ showed the lowest reduction rate of
$E_{1 \mathrm{~mA} / \mathrm{cm}^{2}}$ with $\Delta \alpha / \alpha=-23.3 \%$. a showed the highest value, reaching $\alpha=30$ after application of a stress. However, the $J_{\mathrm{L}}$ value after a stress increased 4-6 times, when compared to the initial value, unlike $\mathrm{E}_{1 \mathrm{~mA} / \mathrm{cm}^{2}}$ and $\alpha$. This is a considerable amount. The variation rates of the breakdown field $\left(\Delta E_{1 \mathrm{~mA} / \mathrm{cm}^{2}} / E_{1 \mathrm{~mA} / \mathrm{cm}^{2}}\right)$ of the nonlinear coefficient $(\alpha / \alpha)$ and of the leakage current density $\left(\Delta J_{\mathrm{L}} / J_{\mathrm{L}}\right)$ after a stress for the specimens at various sintering temperatures are shown in Table 2 .

In light of the degradation results, it is assumed that degradation phenomena are connected to the sintered density and leakage current. The low density of the sintered pellets 
Table 2. $E$ - $J$ Characteristic Parameters before and after DC Accelerated Stress of VMCDNB-doped ZnO Ceramics Sintered at Different Temperatures

\begin{tabular}{|c|c|c|c|c|c|c|c|c|}
\hline $\begin{array}{c}\text { Sintering temp. } \\
\left({ }^{\circ} \mathrm{C}\right)\end{array}$ & $\begin{array}{l}\text { Stress } \\
\text { state }\end{array}$ & $\begin{array}{c}K_{\mathrm{T}} \\
\left(\mu \mathrm{A} \cdot \mathrm{h}^{-1 / 2)}\right. \\
\end{array}$ & $\begin{array}{l}E_{1 \mathrm{~mA} / \mathrm{cm}^{2}} \\
(\mathrm{~V} / \mathrm{cm})\end{array}$ & $\begin{array}{l}\Delta E_{1 \mathrm{~mA} / \mathrm{cm}^{2}} \\
/ E_{1 \mathrm{~mA} / \mathrm{cm}^{2}}\end{array}$ & $\alpha$ & $\Delta \alpha / \alpha$ & $\begin{array}{c}J_{\mathrm{L}} \\
\left(\mu \mathrm{A} / \mathrm{cm}^{2}\right)\end{array}$ & $\Delta J_{\mathrm{L}} / J_{\mathrm{L}}$ \\
\hline \multirow{2}{*}{850} & Initial & - & 5919 & - & 39.1 & - & 35.7 & - \\
\hline & Stressed & 1.38 & 5798 & -2.0 & 30.0 & - 23.3 & 122.9 & 244.2 \\
\hline \multirow{2}{*}{875} & Initial & - & 3370 & & 43.6 & - & 28.2 & - \\
\hline & Stressed & 2.17 & 3249 & -3.7 & 27.1 & -60.9 & 159.19 & 463.7 \\
\hline \multirow{2}{*}{900} & Initial & - & 1871 & - & 37.2 & - & 63.0 & - \\
\hline & Stressed & 5.03 & 1640 & -14.1 & 13.2 & - 181.8 & 401.94 & 538.1 \\
\hline \multirow{2}{*}{925} & Initial & - & 1465 & - & 33.3 & - & 74.1 & - \\
\hline & Stressed & 12.0 & 1204 & -21.7 & 9.6 & -246.9 & 450.72 & 508.3 \\
\hline
\end{tabular}

will yield a more limited conduction path in a multi-junction. Then, it will cause a high current per junction and joule heat at the junction will radiate. On the other hand, the reasons why the high leakage current is generated are 1) a high thermionic emission current because of a lowering barrier and 2) a high recombination current at a junction. The former results in a low nonlinear coefficient, while the latter results in a high leakage current despite the high nonlinear coefficient. The leakage current of these specimens is relatively low when compared to other $\mathrm{Zn}-\mathrm{V}$-based varistors. The weak stability with the increase in sintering temperature can be ascribed to the decrease in the density of the sintered pellets.

\section{Conclusions}

The effect of low-temperature sintering $\left(850-925^{\circ} \mathrm{C}\right)$ on the electrical properties and stability of VMCDNB-doped zinc oxide ceramics was explored. The increase in sintering temperature gradually increased the zinc oxide grain size and decreased the densification of the ceramics because of the volatility of the vanadium species. The breakdown field was lowered because of the increase in the grain size with the increase in sintering temperature. The sintering temperature significantly affected the nonlinear properties and barrier height in the multi-junction. The maximum nonlinear coefficient and barrier height were found at $875^{\circ} \mathrm{C}$. However, the specimen sintered at $850^{\circ} \mathrm{C}$ showed the highest stability against the specified accelerated stress $(0.85$ $\left.E_{1 \mathrm{~mA} / \mathrm{cm}^{2}} / 85^{\circ} \mathrm{C} / 24 \mathrm{~h}\right)$.

\section{Acknowledgments}

This work was supported by Dongeui University grant No. 201802970001.

\section{REFERENCES}

1. M. Matsuoka, "Nonohmic Properties of Zinc Oxide Ceramics," Jpn. J. Appl. Phys., 10 [6] 736-46 (1971).

2. L. M. Levinson and H. R. Philipp, "The Physics of Metal
Oxide Varistors," J. Appl. Phys., 46 [3] 1332-41 (1975).

3. L. M. Levinson and H. R. Philipp, "Zinc Oxide Varistor-A Review," Am. Ceram. Soc. Bull., 65 [4] 639- 46 (1986).

4. T. K. Gupta, “Application of Zinc Oxide Varistor," J. Am. Ceram. Soc., 73 [7] 1817-40 (1990).

5. D. R. Clarke, "Varistor Ceramics," J. Am. Ceram. Soc., 82 [3] 485-502 (1999).

6. X. U. Dong, S. Xiaofeng, C. Xiaonong, Y. Juan, F. Yuee, Y. Hongming, and S. Liyi, "Microstructure and Electrical Properties of $\mathrm{Lu}_{2} \mathrm{O}_{3}$-doped $\mathrm{ZnO}-\mathrm{Bi}_{2} \mathrm{O}_{3}$-based Varistor Ceramics," Trans. Nonferrous Met. Soc. China, 20 [12] 2303-8 (2012).

7. X. U. Dong, W. U. Jie-ting, J. Lei, X. U. Hongxing, Z. Peimei, Y. U. Renhong, and C. Xiaonong. "Highly Nonlinear Property and Threshold Voltage of $\mathrm{Sc}_{2} \mathrm{O}_{3}$ doped $\mathrm{ZnO}-\mathrm{Bi}_{2} \mathrm{O}_{3}$ based Varistor Ceramics," J. Rare Earths, 31 [2] 158-63 (2013).

8. K. Mukae, K. Tsuda, and I. Nagasawa, "Non-Ohmic Properties of $\mathrm{ZnO}$-Rare Earth Metal Oxide- $\mathrm{Co}_{3} \mathrm{O}_{4}$ Ceramics," Jpn. J. Appl. Phys., 16 [8] 1361-68 (1977).

9. K. Mukae, "Zinc Oxide Varistors with Praseodymium Oxide," Am. Ceram. Soc. Bull., 66 [10] 1329-31 (1987).

10. C.-W. Nahm, "The Nonlinear Properties and Stability of $\mathrm{ZnO}-\mathrm{Pr}_{6} \mathrm{O}_{11}-\mathrm{CoO}-\mathrm{Cr}_{2} \mathrm{O}_{3}-\mathrm{Er}_{2} \mathrm{O}_{3}$ Ceramic Varistors," Mater. Lett., 47 [3] 182-87 (2001)

11. J.-K. Tsai and T.-B. Wu, "Non-Ohmic Characteristics of ZnO- $\mathrm{V}_{2} \mathrm{O}_{5}$ Ceramics," J. Appl. Phys., 76 [8] 4817-22 (1994).

12. J.-K. Tsai and T.-B. Wu, "Microstructure and Nonohmic Properties of Binary $\mathrm{ZnO}-\mathrm{V}_{2} \mathrm{O}_{5}$ Ceramics Sintered at $900^{\circ} \mathrm{C}$," Mater. Lett., 26 [3] 199-203 (1996).

13. C.-W. Nahm, "Influence of $\mathrm{Nb}$ Addition on Microstructure, Electrical, Dielectric Properties, and Aging Behavior of MnCoDy Modified Zn-V-based Varistors," J. Mater. Sci.: Mater. Electron., 21 [6] 540-47 (2010).

14. C.-W. Nahm, "DC Accelerated Aging Behavior of Co-Dy$\mathrm{Nb}$ doped Zn-V-M-based Varistors with Sintering Process," J. Mater. Sci.: Mater. Electron., 22 [4] 444-51(2011).

15. C.-W. Nahm, "Effect of Sintering Process on Electrical Properties and Ageing Behavior of $\mathrm{ZnO}-\mathrm{V}_{2} \mathrm{O}_{5}-\mathrm{MnO}_{2}-\mathrm{Nb}_{2} \mathrm{O}_{5}$ Varistor Ceramics," J. Mater. Sci.: Mater. Electron., 23 [2] 457-63 (2012).

16. C.-W. Nahm, "Improvement of Electrical Properties of $\mathrm{V}_{2} \mathrm{O}_{5}$ Modified $\mathrm{ZnO}$ Ceramics by Mn-doping for Varistor Appli- 
cations," J. Mater. Sci.: Mater. Electron., 19 [10] 1023-29 (2008).

17. C.-W. Nahm, "Effect of $\mathrm{Dy}_{2} \mathrm{O}_{3}$ on Microstructure and Electrical Properties of $\mathrm{ZnO}-\mathrm{V}_{2} \mathrm{O}_{5}-\mathrm{MnO}_{2}-\mathrm{CoO}$ Ceramics," J. Mater. Sci.: Mater. Electron., 22 [11] 1674-80 (2011).

18. C.-W. Nahm, " $\mathrm{Nb}_{2} \mathrm{O}_{5}$ Doping Effect of on Electrical Properties of $\mathrm{ZnO}-\mathrm{V}_{2} \mathrm{O}_{5}-\mathrm{Mn}_{3} \mathrm{O}_{4}$ Varistor Ceramics," Ceram. Int., 38 [6] 5281-85 (2012).

19. C.-W. Nahm, "Effect of $\mathrm{Bi}_{2} \mathrm{O}_{3}$ Doping on Microstructure and Electrical Properties of $\mathrm{ZnO}-\mathrm{V}_{2} \mathrm{O}_{5}-\mathrm{Mn}_{3} \mathrm{O}_{4}$ Semiconducting Ceramics," J. Mater. Sci.: Mater. Electron., 28 [1] 903-
8 (2017).

20. J. C. Wurst and J. A. Nelson, "Lineal Intercept Technique for Measuring Grain size in Two-Phase Polycrystalline Ceramics," J. Am. Ceram. Soc., 55 [97-12] 109-11 (1972).

21. M. Mukae, K. Tsuda, and I. Nagasawa, "Capacitance-vsVoltage Characteristics of ZnO Varistor," J. Appl. Phys., 50 [6] 4475-76 (1979).

22. J. Fan and R. Freer, "Deep Level Transient Spectroscopy of Zinc Oxide Varistors Doped with Aluminum Oxide and/ or Silver Oxide," J. Am. Ceram. Soc., 77 [10] 2663-68 (1994). 